\title{
Understanding uncertainty
}

\author{
Derek Richards \\ Editor
}

In this issue of the journal we highlight once again some of the work of Sir Iain Chalmers, one of the leading lights of evidence-based health care, one of the founders of the Cochrane Centre and the first Director of the UK Cochrane Centre. The piece of work in question is the Database of Uncertainties of Treatments (DUETs): this is born out of the work of the James Lind Alliance (http://www.lindalliance.org/) which brings together patients and patient representatives, carers and clinicians, as individuals or represented by groups, to form Priority Setting Partnerships (see page 92) to find out what matters most to patients and clinicians.

In an earlier editorial ${ }^{1}$ I was suggesting that we should learn to accept uncertainty. This in hindsight was probably not correct and the line that I should have been taking is that we should be learning to understand uncertainty. For it is only by identifying where the gaps in our understanding are that we can address them and move forward. The work of the Cochrane Collaboration in conducting reviews of focused questions is a significant contribution to this endeavour, for even though many of them do not find sufficient quality evidence for robust clinical decision making, they do help us understand where our uncertainties lie. The Cochrane reviews are an important contribution to the DUETs database. For those who are interested, a recent paper by Faggion ${ }^{2}$ suggested that in only $22 \%$ of Cochrane oral health reviews, 'was the quality of evidence regarded as adequate for supporting clinical decisions.'

One of the reasons behind my earlier editorial was a concern about didactic approaches to teaching and dogmatic approaches to treatment, when often there was no evidence to support one approach over another. Hopefully, moves towards evidence-based curricula will help to address this, for as one of my favourite quotes from Sir Francis Bacon (1561-1626) goes:-

'If a man will begin with certainties, he shall end in doubts; but if he will be content to begin with doubts he shall end in certainties'.

While we are looking at understanding uncertainty it would be remiss of me not to mention that this is also the name of one of my favourite websites (http://understandinguncertainty.org/). The site is run by David Spiegelhalter, Winton Professor for the public understanding of risk, and his team. The goal of the website is to help improve the way that uncertainty and risk are discussed in society. They frequently tackle errors in the way that statistics are reported, used and abused in the media. Professor Spiegelhalter is also a frequent contributor to More or Less, the Radio 4 programme that tackles the way in which numbers and statistics are used in everyday life and politics.

Finally I have briefly mentioned the Cochrane Oral Health Group, and it is with great pleasure that I note that this year

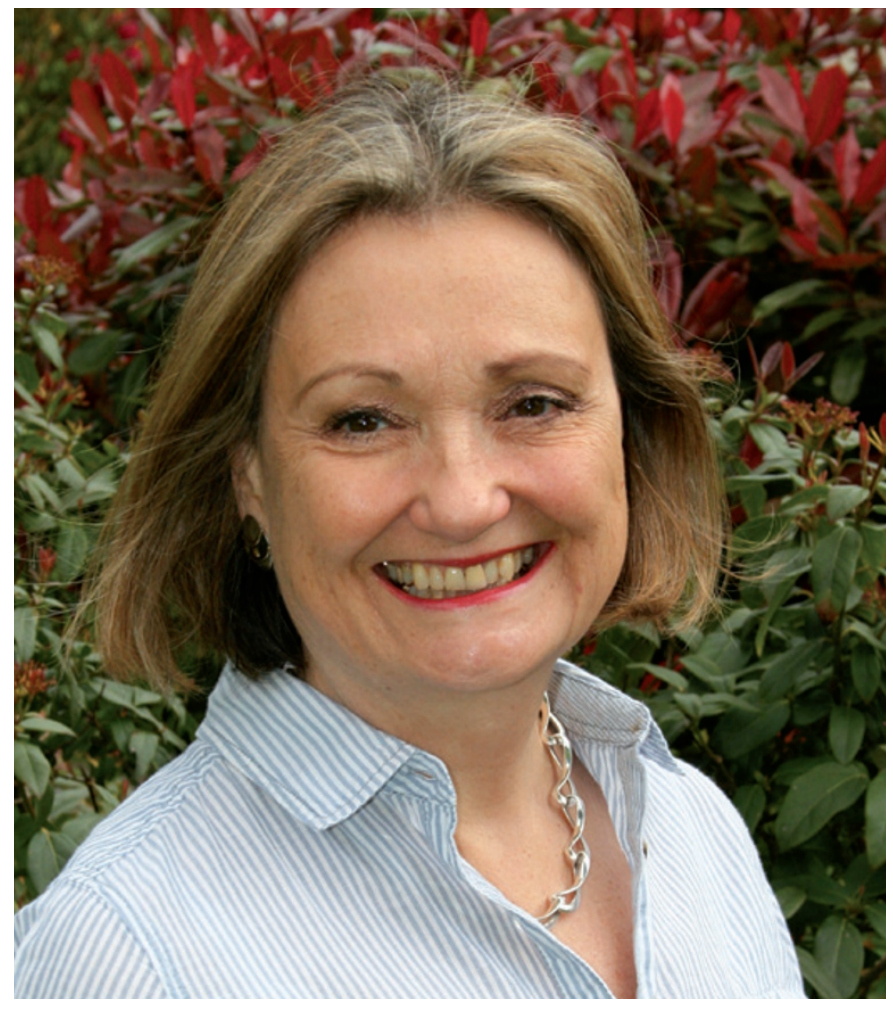

Helen Worthington, Professor of evidence-based care, School of Dentistry at the University of Manchester.

Professor Helen Worthington, professor of evidence-based care in the School of Dentistry at the University of Manchester here in the UK, is the recipient of the 2012 International Association for Dental Research (IADR) H. Trendley Dean Memorial Distinguished Scientist Award in Evidence-Based Dentistry. Helen is the joint Co-ordinating Editor (with Professor Jan Clarkson) and statistician for the Cochrane Oral Health Group, (conducting many Cochrane reviews herself), is a member of Cochrane Co-ordinating Editors Executive and the Cochrane Statistical Methods Group, and is also currently involved in several trials and programme grants, frequently collaborating with groups across the world. Helen's work not just with the Cochrane Collaboration but also within dental statistics over the past 40 years makes her a very worthy winner of the award.

1. Richards D. Accepting uncertainty. Evid Based Dent 2004; 5: 59.

2. Faggion $\mathrm{CM}$ Jr. Is the evidence supporting dental procedures strong? A survey of cochrane systematic reviews in oral health. J Evid Based Dent Pract 2012; 12: $131-134$.

Evidence-Based Dentistry (2012) 13, 68. doi:10.1038/sj.ebd.6400869. 